\title{
Quality of life in the follow-up of uveal melanoma patients after CyberKnife treatment
}

\author{
Annemarie Klingenstein ${ }^{a}$, Christoph Fürweger ${ }^{b}$, Martin M. Nentwich ${ }^{a}$, \\ Ulrich C. Schaller ${ }^{c}$, Paul I. Foerster ${ }^{a}$, Berndt Wowra ${ }^{b}$, Alexander Muacevic ${ }^{b}$ \\ and Kirsten H. Eibl ${ }^{\mathrm{a}}$
}

\begin{abstract}
To assess quality of life in uveal melanoma patients within the first and second year after CyberKnife radiosurgery. Overall, 91 uveal melanoma patients were evaluated for quality of life through the Short-form (SF-12) Health Survey at baseline and at every follow-up visit over 2 years after CyberKnife radiosurgery. Statistical analysis was carried out using SF Health Outcomes Scoring Software and included subgroup analysis of patients developing secondary glaucoma and of patients maintaining a best corrected visual acuity (BCVA) of the treated eye of 0.5 $\log (M A R)$ or better. Analysis of variance, GreenhouseGeisser correction, Student's $t$-test, and Fisher's exact test were used to determine statistical significance. Physical Functioning (PF) and Role Physical (RP) showed a significant decrease after CyberKnife radiosurgery, whereas Mental Health (MH) improved $(P=0.007$, $P<0.0001$ and $P=0.023$ ). $\mathrm{MH}$ and Social Functioning (SF) increased significantly $(P=0.0003$ and 0.026$)$ in the no glaucoma group, $\mathrm{MH}$ being higher compared with glaucoma patients $(P=0.02)$. PF and RP were significantly higher in patients with higher BCVA at the second followup $(P=0.02)$. RP decreased in patients with $\mathrm{BCVA}<0.5$ $\log ($ MAR $)(P=0.013)$. Vitality (VT) increased significantly in
\end{abstract}

\section{Introduction}

Uveal melanoma, as the most common primary intraocular tumor in adults [1], has a reported incidence of 5-7 per million [2]. Despite local tumor control being achieved in the vast majority of cases [3], radical surgery in oncology leading to severe functional and eventually esthetic harm [4] may result in severe effects on patients' quality of life. Enucleation and radiation therapy have different physiological and psychological effects on the patient and these will reflect on their quality of life $[5,6]$.

As there is no difference in survival among the various treatment strategies for uveal melanoma [7], the effect of the treatment chosen on the quality of life of the patient should be considered during treatment planning [8]. In the long-term follow-up of the Collaborative Ocular Melanoma Study group, cumulative all-cause mortality was $43 \%$ among patients in the ${ }^{125} \mathrm{I}$ brachytherapy arm and $41 \%$ in the enucleation arm after 12 years [9]. Five-, 10-, and 12-year rates of death because of histopathologically confirmed melanoma metastasis were 10,18 , and $21 \%$ after brachytherapy and 11,17 , and $17 \%$, patients whose BCVA could be preserved $(P=0.031)$. Neither tumor localization nor size influenced the development of secondary glaucoma or change in BCVA. Although PF and RP decreased over time, MH improved continuously. Prevention of secondary glaucoma has a significant influence on both $\mathrm{SF}$ and $\mathrm{MH}$, whereas preservation of BCVA affects VT. Emotional stability throughout follow-up contributes positively toward overall quality of life. CyberKnife radiosurgery may contribute to attenuation of emotional distress in uveal melanoma patients. Melanoma Res 23:481-488 ( 2013 Wolters Kluwer Health | Lippincott Williams \& Wilkins.

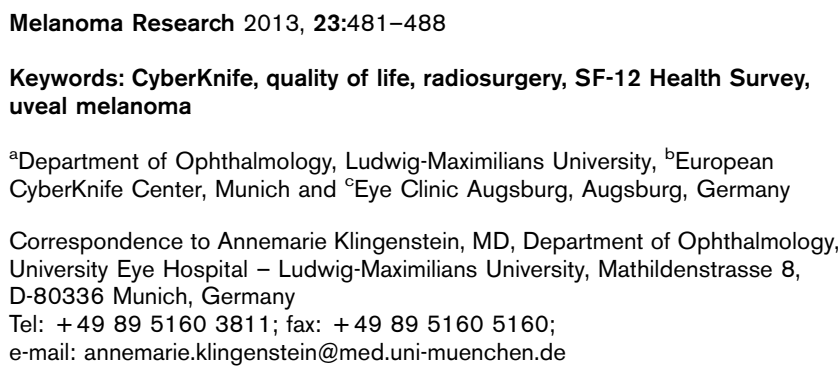

Received 23 January 2013 Accepted 22 August 2013

respectively, after enucleation and thus showed no significant difference [9]. Preservation of vision, and prevention of recurrence and of side effects should be the main goals in patient management along with a cosmetically acceptable result. Enucleation is a physically and psychologically traumatic procedure. To avoid total organ loss, some patients prefer to conserve their eye [10]. The presence of a serious disease can cause depression [11] and compared with other cancer diagnoses and normative data, high proportions of uveal melanoma patients report reduced quality of life and major emotional problems 1 year after surgery $[10,12,13]$. After radiotherapy, fewer signs of deterioration with a decrease in quality of life of only $5 \%$ have been observed [14]. Tumors of at least $6 \mathrm{~mm}$ in thickness remain controversial for suitability for ${ }^{106} \mathrm{Ru}$ brachytherapy and therapeutic alternatives include proton beam radiotherapy, transscleral local resection, endoresection, enucleation, or stereotactic radiosurgery (as Gamma Knife or CyberKnife) [15]. Current designs and techniques of radiation therapy need to be explored [16]. First studies on CyberKnife radiosurgery as a locoregional treatment for uveal 
melanoma showed promising results without serious acute adverse events $[15,17]$.

Precise assessment of physical, mental, and overall quality of life may help improve treatment decision in uveal melanoma patients. Health-related quality-of-life research is indispensible because it provides insights into domains not directly observable [18]. The Short-form (SF-12) Health Survey used in this study assesses physical as well as mental health component summaries in a questionnaire containing 12 items. Table 1 shows the content of the SF-12 used in this study. As enucleation is a radical intervention leading to functional and esthetic impairment with an effect on vitality, physical, emotional, mental health, and social life concepts [19], we have evaluated quality of life in uveal melanoma patients after CyberKnife radiosurgery through SF-12.

\section{Methods}

Quality of life was assessed through the 4-week recall SF-12 Health Survey in 91 uveal melanoma patients (male: female $=48: 43$ ) who had undergone local CyberKnife radiosurgery between November 2005 and September 2011. Detailed patient characteristics are summarized in Table 2. Patients included had been evaluated for radiosurgery treatment eligibility by a dedicated board of tumor specialists from the University Hospital of Munich consisting of ophthalmologists, radiation oncologists, and stereotactic radiosurgeons. CyberKnife radiation was performed as an outpatient procedure. At first presentation as well as at every follow-up visit, apart from radiographic work-up and complete ophthalmological examination including standardized echography, patients were asked to complete the standardized SF-12v2 Health Survey (c) 1992, 2000 Health Assessment Lab, Medical Outcomes Trust and QualityMetric Incorporated, German Version $2.0,10 / 03)$. Informed consent was obtained from all patients when completing the SF-12. All patients were archived in a digital database and the surveys were analyzed retrospectively. They completed at least three surveys [at baseline visit and after a median of 4 and 15 months (mean 3 and 15 months) after therapy]. Clinical data were gathered from the original medical files. The mean values of visual acuity were calculated after transforming the mean angle of resolution values into $\log (\mathrm{MAR})$ values. This study received the approval of the institutional review board of Ludwig-Maximilians University, Department of Ophthalmology, Munich, Germany, and is in accordance with the Declaration of Helsinki.

With the SF-12 as a multipurpose short-form, in only 12 questions, summary physical and mental health can be estimated [18]. Surveys recalled quality of life within the previous 4 weeks. One or more items represent the following eight health concepts: Physical Functioning (PF), Role Physical (RP), Bodily Pain, General Health, Vitality (V'T), Social Functioning (SF), Role Emotional
(RE), and Mental Health (MH). PF ranges from fulfilling vigorous activities without limitations to being very limited in performing all activities including bathing or dressing. RP and RE deal with problems with work or other daily activities as a result of physical health or emotional problems, respectively. SF evaluates interference with normal social activities because of physical and emotional problems. MH notes the frequency of nervousness and depression versus peacefulness, happiness, and calmness [20] (for more details, see Ware et al. [21]). Typically, all scores are transformed into a standardized $(0-100)$ continuous scale, with 50 being the mean and an SD of 10 [19]. Higher scores represent better health, function, and overall quality of life.

SF-12 health surveys were evaluated using the SF Health Outcomes Scoring Software (Qualimetric Inc., Lincoln, Rhode Island, USA). Statistical significance was tested using analysis of variance with Greenhouse-Geisser correction [95\% confidence interval (CI)] and two-tailed Student's $t$-test (Stata/IC 10.1 for Windows; StataCorp LP, College Station, Texas, USA) and Fisher's exact test analyzed by SPSS 20.0 (IBM Corporation, Armonk, New York, USA). For all tests, $P$ less than 0.05 was considered to be statistically significant.

\section{Results \\ Demographic data}

The patients' median age was 63 years at the time of CyberKnife radiosurgery (range 27-86 years). Forty-six patients had uveal melanoma on the right and 45 patients on the left eye. Forty-eight patients were men and 43 were women. Tumor staging through TNM included $\mathrm{T} 1=12, \mathrm{~T} 2=29, \mathrm{~T} 3=45$, and $\mathrm{T} 4=5$ tumors. Ciliary body involvement was present in five patients. Sixty-four tumors were associated with subretinal fluid. Uveal melanomas were located in the peripapillary region $(n=15)$, at the posterior pole $(n=14)$, in the midperiphery $(n=34)$, in the periphery $(n=23)$, and infiltrating the ciliary body $(n=5)$. Median best corrected visual acuity (BCVA) before CyberKnife therapy was 0.5 $\log (\mathrm{MAR})$ and decreased to $1.7 \log (\mathrm{MAR})$ after therapy. Median loss of BCVA was five lines at last follow-up compared with BCVA before therapy. Table 3 shows the development of SF-12 overall quality of life $0-100$ scoring at the baseline visit, and at the first and second follow-up. The categories PF and RP showed a significant decrease after radiotherapy, whereas $\mathrm{MH}$ improved significantly $(P=0.007, \quad P<0.0001$, and $P=0.023$, respectively; analysis of variance, Greenhouse-Geisser correction, 95\% confidence interval for all tables).

Four patients developed metastases throughout the followup period, but the number of these patients was too small to draw definite conclusions on this subgroup. Relevant comorbidities were cardiovascular diseases (arrhythmia, coronary heart disease, status post myocardial infarction, 
Table 1 Content of the 12v2 (English version)

\begin{tabular}{|c|c|c|}
\hline Health concept & Question & Possible answers \\
\hline Physical Functioning & $\begin{array}{l}\text { Are you now limited in moderate activities, such as moving a table, pushing a vacuum cleaner, bowling or } \\
\text { playing golf? } \\
\text { Does your health now limit you a lot, limit you a little or not limit you at all? } \\
\text { How about climbing several flights of stairs? } \\
\text { Would you say your health now limits you a lot, limits you a little, or does not limit you at all? }\end{array}$ & $\begin{array}{l}\text { Yes, limited a lot } \\
\text { Yes, limited a little } \\
\text { No, not limited at all }\end{array}$ \\
\hline Role Physical & $\begin{array}{l}\text { During the past } 4 \text { weeks, how much of the time have you had any of the following problems with your } \\
\text { work or regular daily activities as a result of your physical health? } \\
\text { How much of the time have you accomplished less than you would like? } \\
\text { How much of the time were you limited in the kind of work or other activities you could do? }\end{array}$ & $\begin{array}{l}\text { None of the time } \\
\text { A little of the time } \\
\text { Some of the time } \\
\text { Most of the time } \\
\text { All of the time }\end{array}$ \\
\hline Bodily Pain & $\begin{array}{l}\text { During the past } 4 \text { weeks, how much did pain interfere with your normal work including both outside the } \\
\text { home and housework, would you say ...? }\end{array}$ & $\begin{array}{l}\text { Extremely } \\
\text { Quite a bit } \\
\text { Moderately } \\
\text { A little bit } \\
\text { Not at all }\end{array}$ \\
\hline General Health & In general, would you say your health is excellent, very good, good, fair or poor? & $\begin{array}{l}\text { Excellent } \\
\text { Very good } \\
\text { Good } \\
\text { Fair } \\
\text { Poor }\end{array}$ \\
\hline Vitality & How much of the time during the past 4 weeks did you have a lot of energy? Would you say ...? & $\begin{array}{l}\text { None of the time } \\
\text { A little of the time } \\
\text { Some of the time } \\
\text { Most of the time } \\
\text { All of the time }\end{array}$ \\
\hline Social Functioning & $\begin{array}{l}\text { During the last } 4 \text { weeks, how much of the time has your physical health or emotional problems interfered } \\
\text { with your social activities, like visiting with friends, relatives, etc.? }\end{array}$ & $\begin{array}{l}\text { None of the time } \\
\text { A little of the time } \\
\text { Some of the time } \\
\text { Most of the time } \\
\text { All of the time }\end{array}$ \\
\hline Role Emotional & $\begin{array}{l}\text { During the past } 4 \text { weeks, how much of the time have you had any of the following problems with your } \\
\text { work or other daily activities as a result of any emotional problems, such as feeling depressed or } \\
\text { anxious? } \\
\text { How much of the time have you accomplished less than you would like? } \\
\text { How much of the time did you have trouble doing work or other activities as carefully as usual? }\end{array}$ & $\begin{array}{l}\text { None of the time } \\
\text { A little of the time } \\
\text { Some of the time } \\
\text { Most of the time } \\
\text { All of the time }\end{array}$ \\
\hline Mental Health & $\begin{array}{l}\text { How much of the time during the past } 4 \text { weeks have you felt calm and peaceful? Would you say ...? } \\
\text { How much of the time during the past } 4 \text { weeks have you felt downhearted and blue? }\end{array}$ & $\begin{array}{l}\text { None of the time } \\
\text { A little of the time } \\
\text { Some of the time } \\
\text { Most of the time } \\
\text { All of the time }\end{array}$ \\
\hline
\end{tabular}

Items related to health concepts.

or cerebral stroke) in six, arterial hypertension in 13 , and cancer antecedents in nine patients [breast cancer $(n=4)$, prostate cancer $(n=1)$, skin melanoma $(n=1)$, multiple myeloma $(n=1)$, kidney cancer $(n=1)$, and colon cancer $(n=1)]$. Less commonly, patients presented with diabetes mellitus II $(n=2)$, depression $(n=1)$, Alzheimer's disease $(n=1)$, and chronic hepatitis $\mathrm{C}(n=1)$. Six patients had undergone previous local therapies before CyberKnife (two Gamma Knife, two brachytherapy, one surgical resection, one transpupillary thermotherapy).

Five patients had to undergo retreatment because of local recurrence after CyberKnife (initial tumor staging T1 $=1$, $\mathrm{T} 2=2, \mathrm{~T} 3=2)$.

\section{Subgroup analysis \\ Secondary glaucoma}

Throughout the follow-up period, 30 patients $(33.0 \%)$ developed secondary glaucoma that required topical medication. In addition, three patients needed cyclophotocoagulation, six required application of $1.25 \mathrm{mg}$ intravitreal bevacizumab (Avastin) because of neovascular glaucoma, and one patient required bleb-surgery. Secondary enucleation was inevitable in three eyes during followup. Table 4 shows the development of SF-12 quality of life 0-100 scoring comparing patients who developed secondary glaucoma requiring further treatment throughout follow-up compared with patients who did not need local therapy. There was a difference of 5.2 points or greater for all items in the mean baseline score favoring the glaucoma subgroup. The item MH was significantly higher in the no glaucoma group at the second follow-up $(P=0.02)$. In the no glaucoma group, $\mathrm{MH}$ and $\mathrm{SF}$ increased significantly $(P=0.0003$ and 0.026). Interestingly, $\mathrm{PF}$ decreased significantly within the same group $(P=0.045)$. Figures 1 and 2 show the development of $\mathrm{MH}$ and $\mathrm{SF}$ over time in both groups. Patients requiring local treatment reported a significant decrease in RP $(P=0.032)$. 
Table 2 Patient characteristics $(n=91)$

\begin{tabular}{ll}
\hline Sex & Male : female $(48: 43)$ \\
Median age (years) & 63 (range 27-86) \\
T stage & T1=12 \\
& T2=29 \\
& T3=45 \\
& T4=5 \\
Subretinal fluid & $n=64$ \\
Tumor localization & Peripapillary $(n=15)$ \\
& Posterior pole $(n=14)$ \\
& Midperiphery $(n=34)$ \\
Eye & Periphery $(n=23)$ \\
& Ciliary body $(n=5)$ \\
Relevant comorbidities & Right $(n=46)$ \\
& Left $(n=45)$ \\
& Cardiovascular diseases $(n=6)$ \\
& Arterial hypertension $(n=13)$ \\
& Cancer antecedents $(n=9)$ \\
& Diabetes mellitus $(n=2)$ \\
BCVA $\geq 0.5 l o g(M A R)$ & Depression $(n=1)$ \\
Development of metastases & Alzheimer's disease $(n=1)$ \\
& Chronic hepatitis C $(n=1)$ \\
& $n=30$ \\
& At baseline $(n=47)$ \\
& At second follow-up $(n=17)$ \\
& $n=4$ \\
&
\end{tabular}

BCVA, best corrected visual acuity.

Table 3 Overall quality of life

\begin{tabular}{lcccccc}
\hline & \multicolumn{7}{c}{ Mean score \pm SD } \\
Health & \multicolumn{7}{c}{$\Delta 1$} \\
concept & Baseline & 1 year & year & 2 years & years & $P^{\text {a }}$ \\
\hline PF & $82.3 \pm 26.7$ & $74.1 \pm 29.9$ & -8.36 & $72.7 \pm 31.8$ & -9.83 & 0.007 \\
RP & $75.8 \pm 27.8$ & $70.5 \pm 25.1$ & -5.62 & $67.5 \pm 27.8$ & -8.57 & $<0.0001$ \\
BP & $85.6 \pm 26.8$ & $84.8 \pm 25.7$ & -0.88 & $81.7 \pm 26.1$ & -4.02 & 0.14 \\
GH & $58.5 \pm 20.9$ & $58.3 \pm 18.5$ & -0.15 & $58.2 \pm 17.4$ & -0.30 & 0.86 \\
VT & $59.6 \pm 26.3$ & $63.1 \pm 25.1$ & 3.57 & $57.2 \pm 26.1$ & -2.33 & 0.063 \\
SF & $72.5 \pm 26.3$ & $77.9 \pm 25.7$ & 5.59 & $75.9 \pm 26.4$ & 3.57 & 0.20 \\
RE & $73.3 \pm 26.4$ & $74.1 \pm 27.3$ & 1.07 & $70.8 \pm 26.2$ & -2.28 & 0.27 \\
MH & $65.1 \pm 22.2$ & $71.5 \pm 19.0$ & 6.52 & $70.1 \pm 21.3$ & 5.16 & 0.023
\end{tabular}

0-100 Scoring (transformed scores).

Negative numbers indicate worsening from baseline, positive numbers indicate improvement.

Bold indicates significant values $(P<0.05)$

ANOVA, analysis of variance; BP, Bodily Pain; $\mathrm{Cl}$, confidence interval; $\mathrm{GH}$, General Health; MH, Mental Health; PF, Physical Functioning; RE, Role Emotional; RP, Role Physical; SF, Social Functioning; VT, Vitality.

${ }^{a}$ Repeated-measurements ANOVA, Greenhouse-Geisser correction, 95\% Cl.

There was no significant correlation between tumor size (T-staging) or tumor location (centrally vs. peripherally) and the development of secondary glaucoma $(P=0.80$ and 0.10, Fisher's exact test).

\section{Visual acuity}

We also carried out subgroup analysis of patients with BCVA of $0.5 \log (\mathrm{MAR})$ or higher. At this level, stereopsis and binocularity can be maintained and near-distance vision is above reading ability, which is important for everyday life of patients. The influence of these factors on quality of life was assessed. There was a difference of 6.6 points or greater in PF, RP, Bodily Pain, SF, and RE in the mean baseline score favoring the subgroup with higher BCVA. Patients with higher BCVA had signifi-
Table 4 Quality of life in glaucoma versus nonglaucoma patients

\begin{tabular}{|c|c|c|c|c|}
\hline Score & Baseline & 1 year & 2 years & $P^{\mathrm{a}}$ \\
\hline \multicolumn{5}{|l|}{ PF } \\
\hline Glaucoma & $86.7 \pm 19.4$ & $80.0 \pm 26.0$ & $76.9 \pm 27.7$ & 0.13 \\
\hline No glaucoma & $80.4 \pm 29.5$ & $71.8 \pm 31.2$ & $70.8 \pm 33.5$ & 0.045 \\
\hline$P^{b}$ & 0.34 & 0.25 & 0.41 & \\
\hline \multicolumn{5}{|l|}{ RP } \\
\hline Glaucoma & $82.9 \pm 22.6$ & $75.0 \pm 24.7$ & $72.6 \pm 23.7$ & 0.032 \\
\hline No glaucoma & $72.8 \pm 29.5$ & $68.5 \pm 25.2$ & $65.2 \pm 29.5$ & 0.079 \\
\hline$P^{\mathrm{b}}$ & 0.13 & 0.28 & 0.26 & \\
\hline \multicolumn{5}{|l|}{$\mathrm{BP}$} \\
\hline Glaucoma & $89.2 \pm 23.4$ & $83.9 \pm 24.7$ & $79.6 \pm 26.9$ & 0.13 \\
\hline No glaucoma & $84.0 \pm 28.2$ & $85.3 \pm 26.4$ & $82.6 \pm 26.0$ & 0.43 \\
\hline$P^{\mathrm{b}}$ & 0.43 & 0.82 & 0.62 & \\
\hline \multicolumn{5}{|l|}{$\mathrm{GH}$} \\
\hline Glaucoma & $63.7 \pm 19.3$ & $58.6 \pm 16.5$ & $57.2 \pm 19.5$ & 0.27 \\
\hline No glaucoma & $56.0 \pm 21.1$ & $58.2 \pm 19.5$ & $58.6 \pm 16.5$ & 0.61 \\
\hline$P^{b}$ & 0.10 & 0.94 & 0.73 & \\
\hline \multicolumn{5}{|l|}{ VT } \\
\hline Glaucoma & $65.8 \pm 27.5$ & $67.3 \pm 28.1$ & $55.6 \pm 30.5$ & 0.072 \\
\hline No glaucoma & $56.5 \pm 25.2$ & $61.3 \pm 23.7$ & $57.9 \pm 24.1$ & 0.21 \\
\hline$P^{\mathrm{b}}$ & 0.09 & 0.31 & 0.70 & \\
\hline \multicolumn{5}{|l|}{ SF } \\
\hline Glaucoma & $79.2 \pm 26.3$ & $77.8 \pm 26.3$ & $72.2 \pm 27.2$ & 0.22 \\
\hline No glaucoma & $69.0 \pm 28.5$ & $77.9 \pm 25.7$ & $77.5 \pm 26.1$ & 0.026 \\
\hline$P^{\mathrm{b}}$ & 0.08 & 0.98 & 0.39 & \\
\hline \multicolumn{5}{|l|}{ RE } \\
\hline Glaucoma & $79.2 \pm 21.1$ & $75.9 \pm 29.0$ & $71.3 \pm 26.1$ & 0.17 \\
\hline No glaucoma & $70.0 \pm 28.3$ & $73.3 \pm 26.7$ & $70.6 \pm 26.4$ & 0.22 \\
\hline$P^{\mathrm{b}}$ & 0.09 & 0.68 & 0.90 & \\
\hline \multicolumn{5}{|l|}{$\mathrm{MH}$} \\
\hline Glaucoma & $70.0 \pm 20.1$ & $69.2 \pm 19.4$ & $62.5 \pm 22.2$ & 0.066 \\
\hline No glaucoma & $62.5 \pm 22.8$ & $72.5 \pm 18.8$ & $73.5 \pm 20.1$ & 0.0003 \\
\hline$P^{b}$ & 0.10 & 0.47 & 0.02 & \\
\hline
\end{tabular}

0-100 Scoring (transformed scores).

Bold indicates significant values $(P<0.05)$.

ANOVA, analysis of variance; $\mathrm{BP}$, Bodily Pain; $\mathrm{Cl}$, confidence interval; $\mathrm{GH}$ General Health; MH, Mental Health; PF, Physical Functioning; RE, Role Emotional; RP, Role Physical; SF, Social Functioning; VT, Vitality.

${ }^{a}$ Repeated-measurements ANOVA, Greenhouse-Geisser correction, 95\% Cl.

${ }^{b}$ Two-tailed Student's $t$-test, 95\% Cl.

Fig. 1

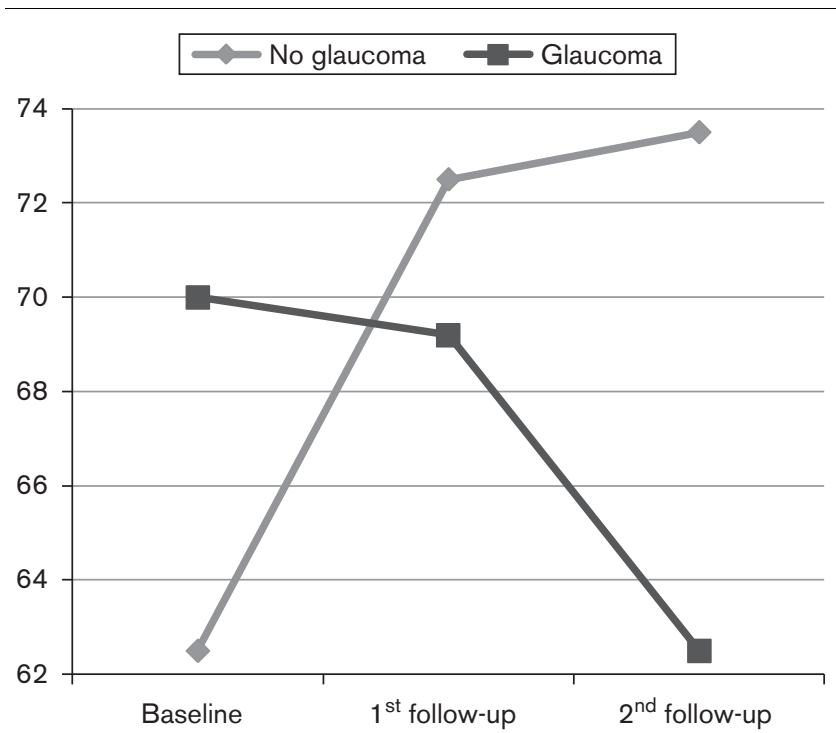

Development of Mental Health in the glaucoma versus the no glaucoma group (0-100 scoring). 
Fig. 2

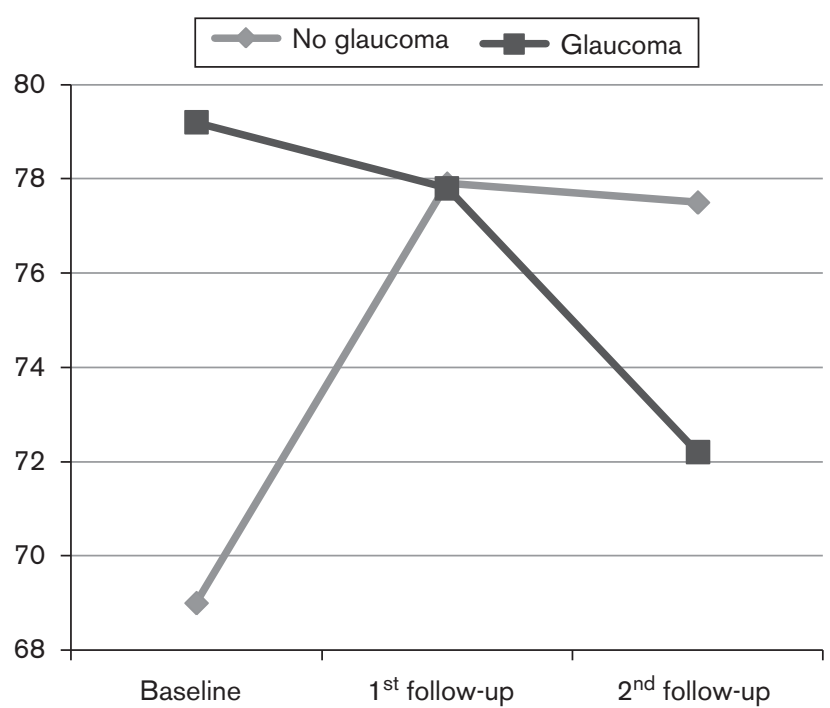

Development of Social Functioning in the glaucoma versus the no glaucoma group (0-100 scoring).

cantly higher values of $\mathrm{PF}$ and $\mathrm{RP}$ at the second follow-up $(P=0.02$, Table 5). Throughout the entire follow-up, RP decreased significantly in patients whose BCVA decreased to below $0.5 \log (\mathrm{MAR})(P=0.013)$. V'T increased significantly in patients whose BCVA could be preserved $(P=0.031)$.

There was no significant correlation between tumor size nor location and visual outcome throughout the follow-up period (Fisher's exact test, $P=0.10$ and 0.37 , respectively).

\section{Male versus female comparison}

Of the 30 patients developing secondary glaucoma throughout follow-up, 18 were men and 12 were women. Of the 17 patients whose BCVA was $0.5 \log$ (MAR) or higher at the 2-year follow-up, nine were men and eight were women. As in the complete patient collective, on comparing quality of life of men versus women, we found a decrease in the categories PF and RP in both subgroups at the 2-year follow-up. The decrease in $\mathrm{PF}$ was significant within the male and in RP within the female subgroup (Fisher's exact test, $P=0.030$ and 0.017 , respectively). After 1 year, MH was significantly higher within the male subgroup, but no significant difference could be found at the 2-year follow-up (Table 6).

\section{Discussion}

In the past few years, a variety of instruments have been introduced to measure quality of life and other patientbased outcomes in healthcare [8]. Treatment success should not only be measured on medical therapy but also on how well the medical team can restore the patient's peace of mind [14].
Table 5 Quality of life in patients with BCVA $\geq 0.5$ compared with $<0.5$

\begin{tabular}{|c|c|c|c|c|}
\hline Score & Baseline & 1 year & 2 years & $P^{\mathrm{a}}$ \\
\hline \multicolumn{5}{|l|}{ PF } \\
\hline$B C V A \geq 0.5$ & $91.2 \pm 15.2$ & $86.7 \pm 18.6$ & $87.5 \pm 20.4$ & 0.67 \\
\hline BCVA $<0.5$ & $81.7 \pm 25.1$ & $70.0 \pm 31.5$ & $67.3 \pm 30.6$ & 0.065 \\
\hline$P^{b}$ & 0.17 & 0.07 & 0.02 & \\
\hline \multicolumn{5}{|l|}{$\mathrm{RP}$} \\
\hline$B C V A \geq 0.5$ & $85.3 \pm 23.1$ & $80.4 \pm 19.4$ & $81.3 \pm 25.0$ & 0.62 \\
\hline BCVA $<0.5$ & $78.7 \pm 25.9$ & $68.2 \pm 25.3$ & $62.0 \pm 26.1$ & 0.013 \\
\hline$P^{b}$ & 0.40 & 0.13 & 0.02 & \\
\hline \multicolumn{5}{|l|}{$\mathrm{BP}$} \\
\hline$B C V A \geq 0.5$ & $91.2 \pm 19.6$ & $90.6 \pm 20.2$ & $90.6 \pm 22.1$ & 0.96 \\
\hline BCVA $<0.5$ & $84.3 \pm 26.1$ & $83.3 \pm 28.6$ & $79.9 \pm 27.3$ & 0.38 \\
\hline$P^{b}$ & 0.35 & 0.38 & 0.10 & \\
\hline \multicolumn{5}{|l|}{$\mathrm{GH}$} \\
\hline$B C V A \geq 0.5$ & $64.7 \pm 19.1$ & $64.1 \pm 15.2$ & $63.8 \pm 21.1$ & 0.87 \\
\hline BCVA< $<0.5$ & $61.5 \pm 21.5$ & $53.7 \pm 19.0$ & $59.0 \pm 19.9$ & 0.27 \\
\hline$P^{b}$ & 0.62 & 0.07 & 0.47 & \\
\hline \multicolumn{5}{|l|}{ VT } \\
\hline$B C V A \geq 0.5$ & $64.7 \pm 19.9$ & $73.4 \pm 19.3$ & $70.3 \pm 18.8$ & 0.031 \\
\hline BCVA $<0.5$ & $61.1 \pm 28.9$ & $61.5 \pm 22.1$ & $54.8 \pm 28.3$ & 0.49 \\
\hline$P^{b}$ & 0.66 & 0.09 & 0.06 & \\
\hline \multicolumn{5}{|l|}{ SF } \\
\hline$B C V A \geq 0.5$ & $79.4 \pm 23.8$ & $87.5 \pm 15.8$ & $79.7 \pm 26.2$ & 0.33 \\
\hline BCVA $<0.5$ & $71.3 \pm 31.5$ & $73.0 \pm 25.9$ & $73.1 \pm 24.4$ & 0.90 \\
\hline$P^{\mathrm{b}}$ & 0.37 & 0.05 & 0.41 & \\
\hline \multicolumn{5}{|l|}{$\mathrm{RE}$} \\
\hline$B C V A \geq 0.5$ & $80.1 \pm 18.8$ & $80.0 \pm 23.0$ & $77.3 \pm 23.4$ & 0.57 \\
\hline BCVA $<0.5$ & $72.1 \pm 27.7$ & $71.2 \pm 28.7$ & $66.3 \pm 21.1$ & 0.58 \\
\hline$P^{b}$ & 0.30 & 0.31 & 0.12 & \\
\hline \multicolumn{5}{|l|}{$\mathrm{MH}$} \\
\hline$B C V A \geq 0.5$ & $65.4 \pm 19.0$ & $71.1 \pm 14.2$ & $78.1 \pm 16.8$ & 0.14 \\
\hline BCVA<0.5 & $66.2 \pm 23.5$ & $71.4 \pm 17.9$ & $70.7 \pm 20.0$ & 0.46 \\
\hline$P^{b}$ & 0.91 & 0.96 & 0.22 & \\
\hline
\end{tabular}

$0-100$ Scoring (transformed scores).

Bold indicates significant values $(P<0.05)$.

ANOVA, analysis of variance; BCVA, best corrected visual acuity; BP, Bodily Pain; $\mathrm{Cl}$, confidence interval; $\mathrm{GH}$, General Health; $\mathrm{MH}$, Mental Health; PF, Physical Functioning; RE, Role Emotional; RP, Role Physical; SF, Socia Functioning; VT, Vitality.

${ }^{a}$ Repeated-measurements ANOVA, Greenhouse-Geisser correction, 95\% Cl.

${ }^{\text {b}}$ Two-tailed Student's $t$-test, 95\% Cl.

The SF-12 is a widely used, practical quality-of-life test with improved efficiency that is rapid to complete. A 4-week recall period was proposed because it was considered that the previous 4 weeks would capture a more representative and reproducible sample of recent health, not unduly affected by daily or momentary fluctuations [22]. In this study, the SF-12 has shown an acceptable quality of life for uveal melanoma patients after CyberKnife radiosurgery with an overall decrease of physical items but stabilization of emotional components over time. Quality of life was not proven to be dependent on the type of radiotherapy applied [14]. MH and SF showed improvement compared with baseline values at the first and second follow-up examination. In an agewise and sex-wise comparable sample, Brandberg et al. [10] reported reduced quality of life, and emotional and cognitive functioning at the 1-year follow-up investigation in both the enucleation and the brachytherapy groups. The levels of anxiety, depression, and emotional problems after radiation therapy or enucleation remain controversial within the literature $[10,23,24]$, with little overall difference during later follow-up [24,25]. 
Table 6 Quality of life comparison of male versus female patients

\begin{tabular}{lcccc}
\hline Score & Baseline & 1 year & 2 years & $P^{\mathrm{a}}$ \\
\hline PF & & & & \\
Male & $81.8 \pm 30.4$ & $73.9 \pm 30.4$ & $71.3 \pm 33.4$ & 0.030 \\
Female & $82.9 \pm 22.0$ & $74.4 \pm 29.3$ & $72.0 \pm 31.8$ & 0.12 \\
$P^{\mathrm{b}}$ & 0.84 & 0.94 & 0.91 & \\
$\mathrm{RP}$ & & & & \\
Male & $76.8 \pm 30.1$ & $69.2 \pm 24.6$ & $69.7 \pm 27.1$ & 0.17 \\
Female & $74.7 \pm 25.2$ & $71.6 \pm 25.6$ & $64.1 \pm 27.9$ & 0.017 \\
$P^{\mathrm{b}}$ & 0.72 & 0.65 & 0.36 & \\
$\mathrm{BP}$ & & & & \\
Male & $84.9 \pm 28.6$ & $84.6 \pm 26.4$ & $81.9 \pm 25.4$ & 0.66 \\
Female & $86.3 \pm 24.8$ & $84.9 \pm 25.1$ & $78.6 \pm 27.9$ & 0.10 \\
$P^{\mathrm{b}}$ & 0.80 & 0.95 & 0.56 & \\
$\mathrm{GH}$ & & & & \\
Male & $58.1 \pm 20.4$ & $59.1 \pm 18.8$ & $54.2 \pm 21.5$ & 0.29 \\
Female & $58.8 \pm 21.7$ & $57.6 \pm 18.2$ & $60.6 \pm 13.9$ & 0.54 \\
$P^{\mathrm{b}}$ & 0.87 & 0.70 & 0.10 & \\
$\mathrm{VT}$ & & & & \\
Male & $59.9 \pm 25.7$ & $65.0 \pm 25.2$ & $58.0 \pm 26.6$ & 0.06 \\
Female & $59.3 \pm 27.3$ & $60.1 \pm 25.3$ & $57.1 \pm 24.9$ & 0.77 \\
$P^{\mathrm{b}}$ & 0.92 & 0.37 & 0.88 & \\
$\mathrm{SF}$ & & & & \\
Male & $72.4 \pm 28.8$ & $78.3 \pm 25.9$ & $76.6 \pm 27.0$ & 0.35 \\
Female & $72.7 \pm 27.7$ & $76.7 \pm 25.8$ & $75.0 \pm 26.2$ & 0.58 \\
$P^{\mathrm{b}}$ & 0.96 & 0.77 & 0.78 & \\
$\mathrm{RE}$ & & & & \\
Male & $73.4 \pm 26.9$ & $78.1 \pm 26.1$ & $73.1 \pm 28.1$ & 0.13 \\
Female & $73.2 \pm 26.1$ & $69.3 \pm 28.0$ & $66.4 \pm 25.5$ & 0.35 \\
$P^{\mathrm{b}}$ & 0.97 & 0.14 & 0.24 & \\
$\mathrm{MH}$ & & & & \\
Male & $68.0 \pm 22.2$ & $75.0 \pm 18.1$ & $73.1 \pm 21.6$ & 0.06 \\
Female & $61.9 \pm 22.0$ & $66.5 \pm 20.2$ & $67.0 \pm 19.5$ & 0.28 \\
$P^{\mathrm{b}}$ & 0.20 & 0.042 & 0.16 & \\
\hline & & & & \\
\hline
\end{tabular}

0-100 Scoring (transformed scores).

Bold indicates significant values $(P<0.05)$.

ANOVA, analysis of variance; $\mathrm{BP}$, Bodily Pain; $\mathrm{Cl}$, confidence interval; $\mathrm{GH}$ General Health; MH, Mental Health; PF, Physical Functioning; RE, Role Emotional; RP, Role Physical; SF, Social Functioning; VT, Vitality.

${ }^{a}$ Repeated-measurements ANOVA, Greenhouse-Geisser correction, 95\% Cl.

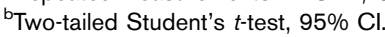

After surgery, the psychological impairment reaches a maximum at 3 months, when the disease-related limitations become noticeable and patients have difficulty returning to their lives [19]. Amaro et al. [19] reported most affection of PF, VT, SF, and MH with a more balanced quality of life after 1 year. For irradiated patients, we found a continuous decrease in PF and RP from the first to the second follow-up, but no dip in the emotional items SF, MH, or VT. Therefore, CyberKnife radiosurgery may help attenuate emotional distress. Possible short-term advantages with respect to $\mathrm{MH}$ after radiation therapy have been published previously [24].

The decrease in PF and RP might be caused by inclusion of patients experiencing the development of a secondary glaucoma or the loss of BCVA over time in Table 3 compared with the subgroup analysis (Tables 4-6). Physical health measures decrease slightly (and consistently with age) over time [24].

In the glaucoma subgroup, SF decreased, but increased significantly in the no glaucoma group. SF is solely based on question 7 of the SF-12 as follows: 'During the past 4 weeks, how much of the time has your physical health or emotional problems interfered with your social activities (like visiting friends, relatives, etc.)?' (SF12v2 Health Survey). The application of topical medication and the frequent measurements of the intraocular pressure are time-consuming procedures and a constant reminder of the primary disease, let alone additional appointments for laser or intravitreal treatment and fear for loss of BCVA.

Loss of vision and the ability to drive a car in particular have a huge impact on quality of life [26]. As preservation of binocular vision and stereopsis is considered to be of great importance for a good quality of life, we included a subgroup analysis with patients who had a final BCVA of $0.5 \log (\mathrm{MAR})$ or higher. These patients also maintained reading ability of the treated eye, independent of BCVA of the partner eye. In the literature, visual impairment is reported by a higher proportion of patients after radiotherapy, whereas significantly higher proportions of enucleated patients reported problems walking on uneven ground and dissatisfaction with their appearance [10]. The COMS QOLS Report No. 3 observed significant differences favoring patients treated by brachytherapy for driving at 1 year and for peripheral vision at 1- and 2-year follow-up [24]. In our study, 17 $(37 \%)$ of 46 patients initially presenting with a BCVA of at least $0.5 \log (\mathrm{MAR})$ maintained a BCVA of at least 0.5 $\log (\mathrm{MAR})$ and reported a significantly better VT. Loss of BCVA was reflected in significantly lower PF and RP. Median loss of visual acuity was five lines at last followup. In comparison, $18 \%$ of eyes at the 1-year follow-up and $34 \%$ at the 2-year follow-up resulted in considerable impairment of BCVA (defined as a loss of six or more lines of visual acuity from the pretreatment level) after ${ }^{125} \mathrm{I}$ brachytherapy of medium-sized choroidal melanomas [27]. The imbalance of different quality of life items at baseline favoring the greater than $0.5 \log$ (MAR) BCVA group is understandable.

Greater tumor prominence, location at the posterior pole, tumor-associated retinal detachment, or tumors that are not dome shaped are most likely to have a poor BCVA outcome within 3 years after therapy [27]. In this study, we could not prove any significance in terms of the size, location, and the development of secondary glaucoma or BCVA.

This study has certain limitations. A longer follow-up is necessary to evaluate the long-term results of radiosurgery. Radiation retinopathy is slowly progressive following radiation exposure [28]. Throughout further follow-up, patients might develop recurrence or painful amaurosis requiring enucleation.

Further, comorbidities might act as confounders considering overall quality of life. It is difficult to evaluate how far loss in quality of life is correlated with which comorbidity. 
As the SF-12 Health Survey measures the general outcome of physical and mental health, it does not focus on ophthalmological quality-of-life parameters. Considering cancer as a serious systemic condition, we find it of great importance to include a core questionnaire such as the SF-12 Health Survey in quality of life evaluation. Questionnaires that are specifically developed for uveal melanoma patients take ophthalmological symptoms such as visual impairment, problems with driving, appearance, and problems reading more into account (e.g. measure of outcome in ocular disease) [8] and can be used additionally in future analyses to optimize the results obtained. Yet, compared with the SF12 survey, this may exceed the recommended maximum of 30 items [29], needing more time and concentration for fulfillment. Additional questionnaires have to be used in conjunction with the core questionnaire [26] possibly influencing the patients' compliance.

We are planning to include the EORTC QLQ-C30 questionnaire in our clinical practice and future analyses. This has been proven to be a reasonable combination previously [30]. The survey was specifically developed to assess the quality of life of cancer patients. The EORTC QLQ-OPT30 module consists of 30 items for uveal melanoma patients receiving treatments other than enucleation [26]. Melanoma-associated or treatment-associated symptoms such as irritation, visual impairment, headache, worry about recurrent disease, problems with driving, problems with appearance, functional problems because of visual impairment, and reading problems can be assessed [26]. Yet, surveys generally do not relate solely to the treated eye and are hence limited in their power. Because of the subjective nature of quality of life testing, it is hard to establish equivalence or invariance of items. Other combinations of quality of life questionnaires used previously for the assessment of quality of life in uveal melanoma patients include the SF-36 Health Survey, the Activities of Daily Vision Scale, the NEI Visual Function Questionnaire, and the Hospital Anxiety and Depression Scale [24] or the Hospital Anxiety and Depression Scale, the EORTC QLQ-C30 (+3), the Impact of Event Scale as well as the Eye Symptom Questionnaire [10], respectively.

These results provide information about the expected quality of life concepts after CyberKnife radiosurgery in uveal melanoma patients. Improvement in $\mathrm{MH}$ can be achieved after radiosurgery and CyberKnife radiosurgery may contribute toward the attenuation of emotional distress. Prevention of secondary glaucoma has a significant influence on both $\mathrm{SF}$ and $\mathrm{MH}$, whereas preservation of BCVA will affect VT. Emotional stability throughout the follow-up period contributes positively toward overall quality of life. Even if the follow-up period chosen was limited in terms of long-term results, it may be of great importance, especially for the older patient. Detailed insights into physical and emotional concepts allow a more individual treatment decision on the basis of patients' preference with respect to visual function, mental distress, and appearance. Ophthalmologists can contribute to the process of rehabilitation by being attentive on returns for consultation.

\section{Acknowledgements Conflicts of interest}

There are no conflicts of interest.

\section{References}

1 Singh AD, Topham A. Incidence of uveal melanoma in the United States: 1973-1997. Ophthalmology 2003; 110:956-961.

2 Hu DN, Yu GP, McCormick SA, Schneider S, Finger PT. Population-based incidence of uveal melanoma in various races and ethnic groups. Am J Ophthalmol 2005; 140:612-617.

3 Gragoudas ES, Egan KM, Seddon JM, Walsh SM, Munzenrider JE. Intraocular recurrence of uveal melanoma after proton beam irradiation. Ophthalmology 1992; 99:760-766.

4 Kornfeld DS. Consultation-liaison psychiatry: contributions to medical practice. Am J Psychiatry 2002; 159:1964-1972.

5 Meliá BM, Moy CS, McCaffrey L. Quality of life in patients with choroidal melanoma: a pilot study. Ophthalmic Epidemiol 1999; 6:19-28.

6 Moy CD, Melia MB. The COMS quality of life assessment in the collaborative ocular melanoma study: design and methods. COMS-QOLS Report No. 1. COMS Quality of Life Study Group. Ophthalmic Epidemiol 1999; 6:5-17.

7 Collaborative Ocular Melanoma Study Group. COMS randomized trial of iodine 125 brachytherapy for choroidal melanoma, III: initial mortality findings. COMS Report No. 18. Arch Ophthalmol 2001; 119:969-982.

8 Foss AJE, Lamping DL, Schroter S, Hungerford J. Development and validation of a patient based measure of outcome in ocular melanoma. Br J Ophthalmol 2000; 84:347-351.

9 Collaborative Ocular Melanoma Study Group. The COMS randomized trial of iodine 125 brachytherapy for choroidal melanoma: V. Twelve-year mortality rates and prognostic factors: COMS report No. 28. Arch Ophthalmol 2006; 124:1684-1693.

10 Brandberg Y, Kock E, Oskar K, af Trampe E, Seregard S. Psychological reactions and quality of life in patients with posterior uveal melanoma treated with ruthenium plaque therapy or enucleation: a one year follow-up study. Eye 2000; 14:839-846.

11 Raison CL, Miller AH. Depression in cancer: new developments regarding diagnosis and treatment. Biol Psychiatry 2003; 54:283-294.

12 Brandberg Y, Månsson-Brahme E, Rindborg U, Sjödén PO. Psychological reactions in patients with malignant melanoma. Eur J Cancer 1995; 31:157-162.

13 Hjermstad MJ, Fayers PM, Bjørdal K, Kaasa S. Health related quality of life in the general Norwegian population assessed by the European Organization for Research and Treatment of Cancer Core Quality of Life Questionnaire: the QLQ-C30 (+3). J Clin Oncol 1998; 16:1188-1196.

14 Chabert S, Velikay-Parel M, Zehetmayer M. Influence of uveal melanoma therapy on patients' quality of life: a psychological study. Acta Ophthalmol Scand 2004; 82:25-31.

15 Zorlu F, Selek U, Kiratli H. Initial results of fractionated CyberKnife radiosurgery for uveal melanoma. J Neurooncol 2009; 94:111-117.

16 Singh AD, Pabon S, Aronow ME. Management of radiation maculopathy. Ophthalmic Res 2012; 48:26-31.

17 Muacevic A, Nentwich M, Wowra B, Staerk S, Kampik A, Schaller U. Development of a streamlined, non-invasive robotic radiosurgery method for treatment of uveal melanoma. Technol Cancer Res Treat 2008; 7:369-374.

18 Desouky TF, Mora PA, Howell EA. Measurement invariance of the SF-12 across European-American, Latina, and African-American postpartum women. Qual Life Res 2012; 22:1135-1144.

19 Amaro TAC, Yazigi L, Erwenne C. Depression and quality of life during treatment of ocular bulb removal in individuals with uveal melanoma. Eur J Cancer Care 2010; 19:476-481. 
20 Ware JE, Kosinski M, Keller SK. SF-36® physical and mental health summary scales: a user's manual. Boston, MA: The Health Institute; 1994.

21 Ware JE Jr, Kosinski M, Turner-Bowker DM, Gandek B. How to score version 2 of the SF-12® Health Survey (with a supplement documenting version 1). Lincoln, RI: QualityMetric Incorporate; 2002.

22 Stewart AL, Ware JE. Measuring functioning and well-being: the Medical Outcome Study Approach. Durham, NC: Duke University Press; 1992.

23 Damato B. Disease and 'dis-ease' in patients with uveal melanoma. $\mathrm{Br} J$ Ophthalmol 2000; 84:343-344.

24 Collaborative Ocular Melanoma Study-Quality of Life Study Group. Quality of life after iodine 125 brachytherapy vs. enucleation for choroidal melanoma. 5-year results from the Collaborative Ocular Melanoma Study: COMS QOLS Report No. 3. Arch Ophthalmol 2006; 124:226-238.

25 Cruickshanks KJ, Fryback DG, Nondahl DM, Robinson N, Keesey U, Dalton DS, et al. Treatment choice and quality of life in patients with choroidal melanoma. Arch Ophthalmol 1999; 117:461-467.
26 Brandberg Y, Damato B, Kivelä T, Kock E, Seregard S. The EORTC ophthalmic oncology quality of life questionnaire module (EORTC QLQОРТ30). Development and pre-testing (Phase I-III). Eye 2004; 18: 283-289.

27 Melia BM, Abramson DH, Albert DM, Boldt HC, Earle JD, Hanson WF, et al. Collaborative ocular melanoma study (COMS) randomized trial of I-125 brachytherapy for medium choroidal melanoma. I. Visual acuity after 3 years COMS report no. 16. Ophthalmology 2001; 108:348-366.

28 Archer DB, Amoaku WM, Gardiner TA. Radiation retinopathy - clinical, histopathological, ultrastructural and experimental correlations. Eye 1991; 5:239-251.

29 Sprangers MAG, Cull A, Groenvold M. EORTC quality of life study group guidelines for developing questionnaire modules. Brussels: EORTC; 1998.

30 Thome B, Dykes AK, Hallberg IR. Quality of life in old people with and without cancer. Qual Life Res 2004; 13:1067-1080. 